\title{
EL CONCEPTO DE “RESIGNACIÓN" EN UN SONETO INÉDITO DE MIGUEL DE UNAMUNO ${ }^{1}$
}

\author{
María Martínez Deyros \\ Universidad de Valladolid \\ mdeyros@hotmail.com
}

\begin{abstract}
RESUMEN: En diversas ocasiones manifestó Unamuno su devoción por el soneto como el cauce adecuado para su expresión poética. Ya en 1907 dedica a esta forma métrica una sección completa en su primer poemario, Poesías. Frente a la postura de la crítica tradicional, que ha considerado siempre este grupo de poemas como fruto de una práctica marginal, y apoyando nuestro trabajo en la novedosa metodología de la crítica genética, se llegará a dos conclusiones importantes: en primer lugar, Unamuno compuso sonetos desde 1894 y estos presentan una unidad temática evidente con el resto de su producción literaria; en segundo lugar, gracias al análisis de sus manuscritos de trabajo, se comprobará cómo don Miguel concibió, en esos primeros años, otro poema que nunca vio la luz y cómo el concepto de "resignación" actúa de hilo conductor de todos ellos.

PALABRAS CLAVE: sonetos, inédito, Unamuno, resignación, borradores, crítica genética.
\end{abstract}

\section{THE CONCEPT OF "RESIGNATION" IN AN UNPUBLISHED SONNET OF MIGUEL DE UNAMUNO}

ABSTRACT: Unamuno devotion was shown repeatedly throughout his sonnet, as the appropriate channel for his expression. There is a whole section in his first poetry book Poesías, which is dedicated to this metric structure. These groups of poems were against the position of traditional criticism as a result of marginal practice. Which supports our work on the new methodology of Genetic Criticism, we uncover two significant conclusions. First, since 1894 he composed sonnets, which

1. Este trabajo se enmarca dentro de la tesis doctoral, Nueva propuesta metodológica en la edición de textos y manuscritos hispánicos: la crítica genética y los borradores de Poesías de Miguel de Unamuno, proyecto cofinanciado por el Banco Santander y la Universidad de Valladolid a través de la "Convocatoria de Contratos Predoctorales de la Universidad de Valladolid para 2013”. 
comprise an obvious thematic unity with the rest of his literary output. Second, through analyzing his drafts we determined that Don Miguel conceived in his earlier years another poem that never saw the light, and how the concept of "Resignation" is represented as a primary thread to all them.

KEYWORDS: sonnets, unpublished, Unamuno, resignation, drafts, Genetic Criticism.

Recibido: 30/03/2015. Aceptado: 02/12/2015

Julián Marías (1968: 5) fue de los primeros críticos que, acertadamente, percibió la "profunda unidad" que subyace en la obra completa de Unamuno, quien logra esa cohesión gracias al recurso de la "reiteración”. A través de la recurrencia semántico-simbólica, nuestro autor consigue dotar de cierta homogeneidad a unos escritos, aparentemente, heterogéneos y dispares. Y este hilo conductor no es otro que el problema ontológico del hombre como ser efímero que aspira a la eternidad. La muerte se convierte en el centro de sus reflexiones metafísicas y lleva a interrogarse al Unamuno agónico sobre su verdadera esencia: ¿morir supone un tránsito hacia la eternidad o hacia el aniquilamiento? ¿hacia el todo o hacia la nada?

Ante la inexorable amenaza que supone la muerte, se abren tres potenciales vías para el hombre: la afirmación de su voluntad, a través de su afán de inmortalidad; la noluntad, es decir, el regreso a la nada; o el llevar una existencia animal o vegetal, ajena por completo a estas cuestiones (Cerezo 1993). La obra completa de Unamuno se muestra como una meditatio mortis y bajo la angustia que le produce el enfrentamiento con el misterio de lo eterno subyace la resignación: "La resignación, la resignación activa, no la pasiva, no consiste en cruzarse de brazos, sino en no volver la vista atrás ni apesadumbrarse por lo irremediable, en comprender que el porvenir es el único reino de la salud" (Unamuno 2007: 441). Frente a la ineludible hora de la muerte, el hombre no debe resignarse a la nada, a dejar de existir sin más. Esta resignación a morir, propia de los débiles, debe ser contrarrestada por el ansia de eternidad de los espíritus fuertes, que luchan por descifrar lo inefable de la experiencia tánica. Y como tal, esta tan solo puede ser revelada por la palabra originaria, es decir, la palabra constituyente o creadora encerrada en lo más profundo de su ser, donde reina la libertad; libertad que hunde sus raíces en el interior de la conciencia y a la que el individuo accederá solo cuando haya sido capaz de enfrentarse consigo mismo. 
La única forma que posee el hombre de convertir en efable el agonismo de la existencia es a través de la poesía, gracias al poder generador de la palabra originaria. De ahí que el propio Unamuno se sintiera ante todo poeta, entendiendo este término en su acepción primaria y etimológica de 'creación', poiesis. Por lo tanto, el poeta deberá descender a su interior, en lucha eterna para lograr la confrontación con su propia conciencia, y no en vano Unamuno ligará este descenso a los inferii con la imagen del agua, símbolo maternal de vida. Así en "No busques luz, mi corazón, sino agua” interpela a su corazón para que huya de la luz en busca del agua, "fuente de la vida”, donde reside el secreto de la eternidad. Como bien analizó Blanco Aguinaga (1975: 286), el agua es un elemento omnipresente en la poética unamuniana, que llega a "simbolizar, junto con la idea de la madre, el anhelo de quietud eterna y de paz inconsciente”. De esta forma, el isotopismo que conforman símbolos como el mar, las aguas, las raíces, la cuna, la fuente o las tinieblas remite a esa verticalidad descendente, a través de la cual el poeta llega a lo profundo de su conciencia.

\section{Génesis del primer soneto unamuniano}

Hasta ahora, la crítica había considerado "Memnón” como el primer soneto unamuniano, o, al menos, era el primero que se había conseguido fechar de forma fiable en torno a los primeros meses de 1900 (García Blanco 1954: 35). Sin embargo, como veremos a lo largo del presente trabajo, habría que retrotraer la data de composición de los primeros sonetos en torno a los años 1894 y 1896. En carta inédita del 6 de febrero de 1896, el escritor Francisco Fernández Villegas aconseja a Unamuno sobre un poema que, recientemente, le ha remitido:

[...] Dice V. en su soneto algo que tengo por paradógico [sic]. Cierto que la audacia secundada por la paciencia horada montes y vence imposibles; pero; ay amigo mío! Esa es la paciencia del pensamiento, no la del sentimiento. Cuando experimentamos un dolor que no tiene remedio, nos resignamos a sufrir porque no podemos sanar. Yo me he resignado algunas veces luchando porque confiaba en vencer. Para las penas que traen aparejada la pérdida de la esperanza no hay lucha. La resignación, cuando V. es una forma de la impotencia; es como el ciego que se resigna a no ver o como el mudo que se resigna a no oir [...] (Carta $\mathrm{n}^{\circ} 6$ del ms. 50/94, Casa Museo Miguel de Unamuno, Salamanca).

Aunque no se indica de forma explícita el título del soneto, por la glosa de Zeda se deduce, claramente, que se trataría de "Resignación”, del cual se han 
hallado hasta tres borradores diferentes, conservados en diferentes carpetas dentro del archivo de la Casa Museo de Miguel de Unamuno en Salamanca: 76/151, 76/149 y 75/105. Los manuscritos de trabajo con signaturas 76/151 y 76/149 resultan ser, sin lugar a dudas, las versiones más antiguas, pues los resultados obtenidos a partir de su cotejo así lo confirman.

Consideramos como el borrador más primitivo el contenido en la carpeta 76/151. Gracias al análisis físico del documento, podemos establecer una primera data orientativa de composición. Como soporte de escritura, don Miguel emplea el verso de una octavilla, del tipo destinado, por norma general, a la textualización de "copias en limpio" o "definitivas". En el recto del folio, se observa parte de la traducción de la obra El progreso, su ley y su causa de Herbert Spencer. Entre 1893 y 1895 fueron cinco los títulos de Spencer traducidos por Unamuno y publicados en España. Para Fioraso (2014: 222), aunque sin atreverse a indicar una fecha concreta, El progreso vio la luz antes que las dos últimas, De las Leyes en general y Exceso de legislación, publicadas en La España Moderna en 1895. En nuestra investigación, la primera mención que encontramos en $L a$ España Moderna a la citada obra de Spencer sobre el progreso se remonta al mes de septiembre de 1894, en cuyo número LXIX aparece incluida en la sección “Obras nuevas”. Por lo tanto, cabría fechar la octavilla con signatura 76/151 antes de septiembre de 1894. Como se puede observar a partir de su transcripción diplomática, el soneto revela un estado de textualización bastante avanzado. Asimismo, consideramos la tachadura en el verso 3 como una variable inmediata o de escritura (Blasco 2011: 161), es decir, aquella que se habría producido al filo de la pluma y que vendría motivada por un más que probable lapsus del autor, al saltar una línea de verso durante la copia. De todo esto se deduce que Unamuno, con toda seguridad, transcribió la versión de este soneto de otro borrador previo²

\footnotetext{
Ms. 76/151 (1 $1^{\text {a }}$ redacción conservada)

Resignación! humana omnipotencia

Del amor manantial y lecho puro

Fruto en la mente de la ea

Al corazón desciende, ya maduro

Fruto en la mente de la casta ciencia.
}

2. A continuación, presentamos el significado de los diferentes signos empleados en la transcripción: [palabra]: palabra tachada y eliminada de la versión.

[palabra] ${ }^{\text {palabra : }}$ palabra tachada y sustituida por otra en espacio interlineal.

[palPalabra]: en cursiva se señalarán las palabras que evidencien una sobreescritura: en cursiva simple, se indicará el primer estrato; en cursiva con negrita, el segundo. 


\author{
Préstanos ${ }^{<\text {Activa y }>}$ Rresignadación persistencia $<$ activa á la conciencia $>$ \\ Para luchar con el presente impuro \\ Sin tregua, en el combate eterno y duro, \\ $<$ Préstale>Préstando ${ }^{<\text {Đando }>}$ audacia y á la vez paciencia. \\ Sin odio, de piedad el pecho lleno

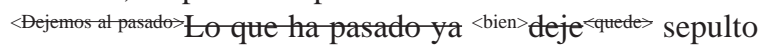 \\ $<$ Al pasado dejemosle $>$ \\ De la memoria en la tranquilo seno \\ Y sin turbar su paz con un insulto \\ Rinda por siempre el ánimo sereno \\ Culto de acción al porvenir oculto.
}

El resto de tachaduras habrían tenido lugar en un momento posterior al acto de escritura, cuando el autor se dispone a leer su manuscrito y a corregir e introducir las variables oportunas. Este tipo de variantes se conocen como mediatas o de lectura, reflejándose, en general, en el espacio interlineal de los versos o en los márgenes de la superficie de la página, señaladas en nuestra transcripción con una tipografía de menor tamaño. El tipo de trazo empleado en las tachaduras permite leer sin complicaciones el segmento cancelado y, según la función que el poeta otorga a dichas ratures ${ }^{3}$, estas se corresponden con dos tipos de operaciones: de sustitución, en la mayor parte de los casos, en donde el elemento suprimido es reemplazado por otro; y de desplazamiento, a través del cual se produce la inversión de dos versos enteros, el primero y el último del segundo cuarteto. En estos endecasílabos, con toda probabilidad, primeramente habrá realizado las sustituciones pertinentes y solo, en un ulterior momento, habrá decidido trastocar su orden.

En este punto, es inevitable recordar aquellos apuntes de su Diario Íntimo en que retoma las palabras del primer verso: "El que quiere todo lo que sucede consigue que suceda cuanto quiera. Omnipotencia humana por resignación. Mas no comprendía que a tal resignación sólo por la gracia se llega, por la fe y la caridad" (Unamuno 2005: 267). El hombre dispone de un arma inquebrantable en su lucha por el más allá y esta no es otra que la resignación; pero una resignación "activa a la conciencia", que no es solo "fruto" de la razón de la "casta ciencia”, sino que se ha forjado a través del sentimiento. Más adelante veremos el isomorfismo simbólico del agua y de la maternidad, relacionado con el subconsciente o intraconsciente unamuniano, que recorrerá de forma insistente los

3. Para la Critique Génétique la tachadura (rature) se convierte en un elemento indispensable, pues en ella se encuentran las huellas del proceso de escritura: "la rature est un des éléments capables de témoigner de la dimension temporelle propre à tout processus d'écriture” (Grésillon 1994: 67). 
poemas analizados en el presente trabajo. Por ahora, baste señalar la semajanza de las anotaciones que don Miguel realizó en 1897 en su diario privado con los versos que ya había escrito unos años antes.

Para la redacción del segundo borrador conservado, el incluido en la carpeta 76/149, Unamuno se sirvió de un papel de características similares al anterior. Reutiliza el verso de una octavilla, en cuyo recto se aprecia la redacción de un borrador en prosa de un texto sin identificar. Al igual que en el caso anterior, la escritura del soneto se desarrolla en el verso del folio, con la página en sentido vertical y con el mismo útil de escritura, una estilográfica de tinta negra. A pesar de no poder proporcionar una data precisa para este manuscrito de trabajo, de su cotejo con la versión del ms. 76/151 se concluye que pudiera haber sido escrito en fechas cercanas y siempre antes de febrero de 1896, pues el término "audacia” de los versos 10 y 5, presentes en los ms. 76/151 y 76/149 respectivamente, vendría a coincidir con el comentario que realiza Fernández Villegas: "Cierto que la audacia secundada por la paciencia horada montes y vence imposibles”, y que, posteriormente, Unamuno cambiará por “osadía”, manteniéndolo hasta la versión impresa de 1907.

\author{
Ms. 76/149 (2a redacción) \\ Resignación! humana omnipotencia \\ Del amor ${ }^{<\text {vigor }>}$ mantan manantial y lecho puro \\ Al corazón desciende ya maduro \\ Fruto en la mente de la casta ciencia \\ Audacia presta y á la vez paciencia \\ Para luchar con el presente impuro \\ Sin tregua, en el combate eterno y duro \\ Resignación activa! á la conciencia \\ Para que luche en el combate impure ${ }^{<d u r o>}$ \\ Del ideal, con el presente impuro \\ Resignación activa! á la conciencia. \\ Sin odio, de piedad el pecho lleno \\ <Respetad> $\mathrm{Al}$ pasado dejemoste ${ }^{<y a>}$ sepulto \\ De la memoria en el tranquilo seno \\ Y sin turbar su paz con un insulto \\ Rinda por siempre el ánimo sereno \\ Culto de acción al porvenir oculto.
}

Como en el manuscrito de trabajo anterior, apreciamos dos tipos de variantes de autor bien diferenciadas: por un lado, las variables inmediatas, producto de 
un lapsus calami, en el segundo verso, al escribir la palabra "manantial”; además de una retractación operada en el mismo acto de escritura, que afectaría a los tres últimos endecasílabos del segundo cuarteto; y, por otro lado, las variables mediatas, con claros signos de reescritura surgidas en un momento posterior de revisión y lectura. Con respecto a estos cambios, cabe destacar la inmovilidad del último segmento o palabra del verso, frente a la extrema volatilidad del resto del endecasílabo. La cancelación de los tres versos centrales no viene a alterar en sí el contenido del soneto, pero creemos que está motivada por la intención de dotar de una mayor subjetividad al poema, sustituyendo la forma impersonal del verbo, "luchar", por el subjuntivo "luche".

Por otro lado, destaca el mantenimiento de las mismas palabras en el remate de los versos a fin de no romper la rima. En diversas ocasiones manifestó Unamuno su predilección por esta forma estrófica. Así, en el prólogo a su poemario De Fuerteventura a París expresó el placer suscitado al encerrar el sentimiento "en un cuadro rígido, en una forma fija, cuando se consigue hacer un diamante de palabras con sus catorce facetas lisas y brillantes y sus cortantes aristas" (Unamuno 1999: 757). Sin embargo, no olvidemos que estas declaraciones datan del año 1925, es decir, treinta años después de la redacción del soneto "Resignación”. Cuando don Miguel publica sus Poesías, en abril de 1907, es de sobra conocida su adversión hacia la rima generatrice, buena solo para quien "hace poesía de fuera a dentro", al modo de la poesía sensualista de Rubén Darío (Robles 1996: 276). De la misma forma, desprecia "el consonante" por parecer "artificio de música tamborilesca, de hotentotes o bechuanas” (Blázquez 2007: 303). No obstante, y a pesar de consagrar una pequeña sección al soneto dentro de su primer poemario, no se reconocerá abiertamente partidario de la rima "engendradora” hasta el año 1910 (Imízcoiz 1996: 245), cuando aceptará que no se trata de un mero ornato exterior y que es capaz de conceder al poeta libertad y generar, por sí sola, pensamiento. Así, en el soneto XXV de De Fuerteventura a París, antepone el epílogo: "Buscando palabas para los sonetos”, y cierra la composición con una glosa en la que explica una vez más esta fuerza creadora de la rima y lo ejemplifica con algunos de los poemas incluidos en ese mismo poemario del destierro:

Sabido es lo que se llamó rima engendradora, y todo el que hace versos conoce el valor de sugestión de un consonante obligado para colocar el cual surge una metáfora. Es el azar, maestro de libertad encadenada. Así en el soneto XVII, por ejemplo, la rima de venablo, establo, hablo y San Pablo. O en el XXII las rimas en agua (Unamuno 1999: 782). 
Por lo tanto, don Miguel aceptará de buen grado el uso de la rima, siempre y cuando no limite "el pensamiento", sino que sirva para "potenciarlo" (Celma 2002: 99). Ya en 1969, el hispanista polaco von Prellwitz en su trabajo doctoral sobre los sonetos unamunianos confirmaba, a partir del análisis de ciertos borradores pertenecientes a Rosario de Sonetos Líricos, que Unamuno se dejaba guiar, a menudo, por las rimas inspiradoras de pensamiento. En nuestra investigación, hemos confirmado que en numerosos manuscritos de trabajo, que presentan un estado redaccional no muy avanzado de algún poema, don Miguel se servía de series de listas de palabras, con una misma rima y que, por lo general, solía anotar en los márgenes de las páginas. No es el caso de los borradores conservados sobre "Resignación", porque, como hemos apuntado en un principio, se trataría en los tres casos de versiones en un proceso redaccional bastante avanzado. Sin embargo, a pesar de la amplia labor compositiva que debió de preceder a estos manuscritos objeto de nuestro estudio, se aprecia esa intención de mantener la misma rima, aunque para ello deba reemplazar el resto del endecasílabo.

El tercero de los borradores se conserva en la carpeta 75/105, junto con la versión de otros once sonetos, algunos escritos en fechas cercanas (Martínez Deyros 2015a). En esta versión, el poema aparece con su título definitivo, "Resignación”, escrito en el margen izquierdo de la hoja, la cual presenta el tamaño de una cuartilla doblada a la mitad, a modo de libreto, empezando la escritura en la página 1, cara derecha del recto, y siguiendo por la página 2, cara izquierda del verso, y la página 3, cara derecha del verso. Nuestro soneto ocupa la tercera posición, en la página 2, precedido de "Fortaleza" y "Piedad”, y seguido del inédito “Hai benYocdán” y del también publicado en 1907, "Fe”.

\author{
Resignación, humana omnipotencia \\ Del valor manantial y lecho puro \\ Baja á mi pecho<corazón>, grano ya maduro \\ Que en mi mente la divina ciencia \\ Presta osadía y á la vez paciencia \\ Para luchar en el combate duro \\ Puesta su vista en el confín futuro \\ Resignación activa, á mi conciencia. \\ Sin odio y de piedad el alma henchida \\ Tomándote en firme fundamento \\ Siga el recto camino de mi vida \\ A conquistar el porvenir atento \\ Reino de libertad que nos convida \\ A poner en su suelo nuestro asiento
}


A medida que avanza la redacción del poema, se desarrolla una subjetividad más pronunciada. En efecto, logra esta gradación a través de los determinantes pronominales de primera persona: "mi corazón”, “mi mente”, "mi conciencia”, precisando y limitando, de esta forma, la experiencia íntima y personal. Sin lugar a dudas, los tercetos sufren la transformación más brusca, mientras que los cuartetos, apenas presentan variables. No obstante, es necesario detenernos en el cambio operado en el verso 2, donde sustituye, en principio, el término "amor", por "vigor" y, finalmente, por "valor". Esta permutación encuentra su lógica dentro del contexto poético unamuniano, donde la "resignación activa” y agónica son cualidades del hombre fuerte, en contraposición con la "resignación pasiva", propia de los débiles de espíritu, que se conforman ante la muerte total, ante la nada. De esta forma, cobra todo su sentido el reemplazo de "amor", por "vigor" y "valor"; atributos que en otras ocasiones se verán reforzados por los términos, "fuerte" y "fortaleza". Asimismo, la "audacia" del verso 5 es reemplazada por "osadía”, palabra también llana y afín en significado. Además, es necesario señalar en este mismo verso un desplazamiento operado entre las dos primeras palabras del endecasílabo: "Audacia presta” por "Presta osadía”. En este caso, se trataría de una tachadura invisible ${ }^{4}$, pues en el borrador previo, ms. 76/149, esta inversión de términos no ha sido indicada mediante ningún tipo de signo. En efecto, esto podría apoyar nuestra hipótesis de que hubo, necesariamente, de existir, al menos, otro manuscrito intermedio entre ambas versiones. De la misma forma, se explicaría la variación de los tercetos, donde el poeta llega a cambiar, por completo, la rima consonante en -eno, - ulto, por -ida, -ento. En la tercera versión, Unamuno ya no hará referencia al "pasado ya sepulto”, y focalizará su expresión en la exaltación de las virtudes (piedad, firmeza y rectitud) necesarias para la conquista del futuro, de ese "porvenir atento", que es el "reino de libertad”. De ahí, que en los cuartetos ponga en su punto de mira "el confín futuro” y prescinda, también en este caso, de la mención al "presente impuro".

La última versión de la que disponemos coincide con el texto impreso en 1907. Incluido en el poemario ocupando la tercera posición dentro de la sección dedicada a los sonetos, presenta escasas variables en los cuartetos con respecto al borrador anterior de la carpeta 75/105. En efecto, en el verso 4 apreciamos el verbo "sembró", ausente en la versión precedente, y creando, por ello, un verso decasí-

4. Grésillon establece tres tipos de tachaduras: visibles que "permettant en général au lecteur de restituer l'écrit rature"; no visibles que "ne permettant pas de restituer l'écrit primitif” y las invisibles "non visible au premier coup d'oeil, consiste en des réescritures successives, souvent sur des folios différents, sans que les versions dépassées soient marquées comme caduques. Ce procédé est fréquent chez des auteurs qui ont un horreur physique de la rature” (Grésillon 1994: 67). 
labo. Desde nuestro punto de vista, se trata de un caso de omisión involuntaria, un lapsus cometido al copiar el poema a partir de otro manuscrito. La última variable afectaría al verso 7, en donde se sustituye el determinante posesivo en el sintagma "su vista", por el artículo determinado femenino, "la vista", recurriendo, de este modo, a la generalización y ligándola, como veremos en el siguiente apartado, con la "visión”, como acto fundamental de la imaginación, que procede del corazón.

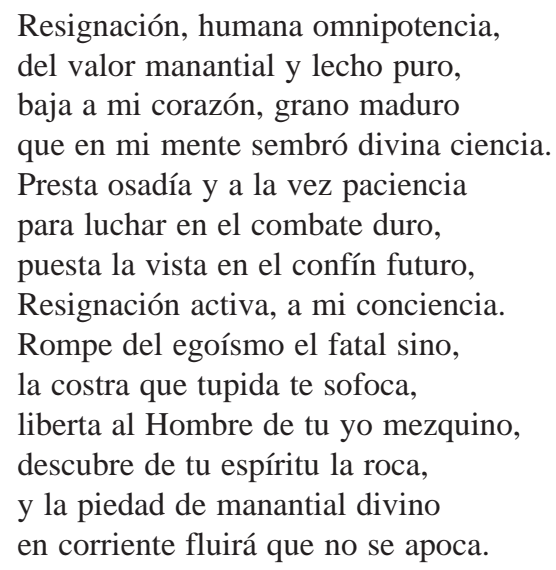

Ahora bien, será en los tercetos donde se produzca el cambio más llamativo, llegando a sustituir los seis versos por completo. Observamos que en los últimos endecasílabos de las tres versiones autógrafas, centra su atención en la "piedad" que debe residir en el alma (o "pecho"), para ser capaces de dejar atrás el pasado, sin injuriar su "memoria" oculta en el "tranquilo seno", y mirar, en su lugar, hacia el futuro, al "porvenir oculto" o "atento", que es también "reino de libertad". Sin embargo, en la versión impresa y, por lo tanto, definitiva de 1907, la estructura y sentido de los tercetos resulta ser completamente diferente. Aunque la idea pudiera parecer similar, se expresa de un modo diverso; ya no se solicita "piedad" y seguir "el recto camino", sino que, en consonancia con ese espíritu agónico de los cuartetos, se exige a esa "resignación activa” el romper con el "fatal" destino, con ese egoísmo que es "costra" que sofoca la personalidad del hombre. Llegados a este punto, resulta inevitable pensar en su ensayo "Soledad", publicado en 1905, donde compara los espíritus con crustáceos: "Así sucede en realidad; todos somos pobres cangrejos encerrados en dura costra”. Será el poeta el único capaz de sacudir dichos espíritus de tal forma que consigan agitarse y, chocando entre ellos, romper el caparazón, mezclándose, en última instancia, unos espíritus con otros en "el alma de la humanidad". A esta se refiere con el "Hombre" del soneto, pues si conseguimos 
desembarazarnos de nuestra "costra”, liberaremos a la entera humanidad, el "Hombre" con mayúsculas, de la mezquindad y de su fatal destino. Una vez libertada el alma, descubrirá la fortaleza y la piedad que fluirá en "corriente" de "manantial" divino. El simbolismo del agua, ya sea como mar, fuente, aguas subterráneas, lago u océano, representa "el abismo feminizado y maternal que para numerosas culturas es el arquetipo del descenso y el retorno a las fuentes originales de la felicidad" (Durand 2005: 232). Y no será menos para Unamuno, donde el isomorfismo del "agua” y del regazo materno será motivo recurrente en toda su obra.

Para finalizar este apartado, conviene detenernos, brevemente, en el cambio drástico operado en los tercetos del soneto "Resignación". Si se observa el tercer borrador, presente en la carpeta $75 / 105$, a simple vista, se podría pensar que estamos ante una copia en limpio de los poemas allí incluidos, pues apenas presentan tachaduras ni signos evidentes de reescritura. Sin embargo, si cotejamos las versiones de estos tres sonetos con el texto definitivo de 1907, nos daremos cuenta de un cambio sustancial; y es que Unamuno ha intercambiado los tercetos de los tres sonetos. Así, los versos que, originariamente, concibe para "Resignación", finalmente, pasarán a formar parte de "Fortaleza", los de "Fortaleza" de "Piedad" y los de "Piedad" de "Resignación". Dudamos de que esta versión, presente en la carpeta 75/105, sea algo ocasional, pues en 1902 Juan Valera incluirá, con esta misma estructura, los sonetos "Fortaleza” y "Piedad”, junto con “Al sueño", en su Tomo IV del Florilegio de poesías castellanas del siglo XIX, volumen que comienza a componer en marzo de 1902 (Valera 2008: 270) y no verá la luz hasta diciembre de ese año (321). Cotejando ambas versiones, podríamos incluso llegar a admitir que este manuscrito, 75/105, se tratara del borrador, o de una copia del mismo, que utilizara Valera para su antología, pues no presentan ninguna variable.

Por lo tanto, podemos afirmar que Unamuno vendría trabajando en su soneto "Resignación” desde el año 1894 hasta principios de 1896, fecha en que tenemos la certeza de que lo remitió a uno de sus corresponsales habituales, Francisco Fernández Villegas. No obstante, no podemos sostener que tardara casi dos años en elaborar una primera extensión de esta composición, pues no se han conservado más testimonios de este proceso redaccional y, siempre cabe la posibilidad de que enviara estos versos con anterioridad a más personas. Sin embargo, sí poseemos la seguridad de que este soneto sufrió posteriores reescrituras y así lo atestigua el manuscrito de trabajo de la carpeta $75 / 105$, donde se presenta en la primera cuartilla junto con otros cuatro: "Fortaleza", "Piedad", "Hai ben Yocdán” y "Fe". Sabemos, por el borrador de un prólogo conservado en la Casa Museo de Unamuno, con signatura 76/129, que estos cinco sone- 
tos, formaban parte del elenco de poemas que Unamuno planeaba incluir en la segunda fase redaccional de Poesías. Si el proyectado poemario se empieza a concebir, en torno al año 1899, con tan solo once composiciones, a lo largo de 1900 don Miguel ve aumentado su corpus poético de forma notable, lo que le impulsa a plantear un volumen más amplio, que contenga hasta veintisiete poesías. Estos cinco sonetos, anteriormente citados, junto con "Memnón”, formarían parte del bosquejo inicial de la obra. Por lo tanto, no nos resulta extraño encontrar en la misma carpeta 75/105 otra cuartilla, con una versión de “Memnón”, muy cercana, por cierto, al texto definitivo de 1907. Los alógrafos hallados confirmarían que, entre 1900 y 1902, Unamuno trabajó de nuevo en su soneto "Resignación" y, como se desprende del cojeto de sus borradores, entre la versión de la carpeta 76/149 y la de la carpeta 75/105 tuvieron que existir, necesariamente, otros borradores intermedios en los que su autor incorporó ulteriores cambios en la textualización del poema.

En efecto, no disponemos de más datos que atestiguen las siguientes reescrituras de "Resignación”, hasta llegar a la versión definitiva de 1907. Tampoco se conservan otros manuscritos de los sonetos "Fortaleza" y "Piedad", que nos permitan indicar, al menos de forma aproximada, una fecha orientativa de composición y de reelaboración. Sin embargo, creemos que don Miguel tuvo que trabajar en la redacción de los tres poemas, si no al mismo tiempo, en fechas muy cercanas, concibiéndolos como una misma unidad; aunque a falta de otros documentos, nunca sabremos a ciencia cierta cuándo su autor decidió retocarlos y dotarlos de su estructura definitiva.

En cambio, sí que podemos resaltar la estrecha ligazón, tanto de contenido como formal, que une a los tres sonetos ("Resignación”, "Piedad” y "Fortaleza"), lo que nos hace suponer que fueran escritos de forma contemporánea. Esta cohesión se muestra hasta en el particular modo de concebir su estructura, donde los cuartetos representarían la parte fija e inmoble de un mismo mecanismo, mientras que los tercetos actuarían como los versos móviles, cuyo cambio de posición no revelaría, en sustancia, importantes divergencias de significado. Asimismo, la apelación dialógica, presente en los tres sonetos, concentra en el yo poético una pluralidad de sujetos, poniendo en comunicación al poeta consigo mismo.

\section{Edición de un soneto inédito}

El concepto de la resignación activa actúa como hilo conductor de todos los poemas, hasta ahora presentados aquí y que fueron publicados en vida por el 
propio autor. Sin embargo, no fueron los únicos sonetos que don Miguel concibió en torno a esta temática. Así, en los manuscritos de trabajo de las carpetas 76/151 y 76/149, apreciamos otros dos intentos de textualización de otros poemas, en la mitad inferior de la página. En el primer caso, se trataría de una composición incompleta, pues su autor tan solo llegó a desarrollar los cuartetos y estos presentan un estado bastante embrionario. Ahora bien, en el segundo borrador, nos encontramos ante una situación completamente diferente. Aquí, el segundo poema sí que posee una estructura claramente definida, con catorce versos, sin título y sin apenas signos de reescritura. Para la presentación de este documento inédito, optamos, al igual que en los casos anteriores, por su transcripción diplomática, a fin de respetar la voluntad de su autor de no darlo nunca a la luz y de dar cuenta de las diversas variables y del estado redaccional en el que se encontraba dicho soneto ${ }^{5}$.

\author{
Del insondable fondo del oceano \\ Do ta muertas< <yacen las> memorias, surge lenta \\ La visión pura ${ }^{<d e l ~ f u t u r o>}$ en que robusta ${ }^{<\text {donde> }}$ asienta \\ La libertad su arbitrio soberano \\ Velado Porvenir, eterno arcano, \\ Savia en que la esperanza se alimenta \\ Tú $e$ Eres el campo libre <la fuente viva> que sustenta \\ En el alma el aliento sobrehumano \\ Siempre adelante, sin cesar avanza \\ ElCon paso firme, la mirada altiva \\ Que el varón fuerte de tal modo alcanza \\ Para luchar resignación activa

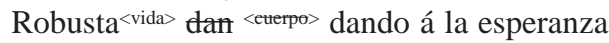 \\ De los recuerdos con lael alma viva.
}

Como se observa en la transcripción diplomática, fueron pocos los cambios operados en esta versión bastante avanzada del poema. Probablemente, don Miguel copiara de otro borrador anterior la textualización de este soneto, sobre el que efectuó varias reescrituras en un posterior momento de lectura. Por lo tanto, las escasas variantes de autor que hallamos se corresponderían con el tipo de variables mediatas o de lectura, realizadas por el poeta después del propio acto de escritura, ocupando por ello el espacio interlineal entre los versos. Asimismo,

5. Para profundizar más sobre la edición de poemas inéditos, de los que conservamos tan solo un borrador, véase el artículo "Soledad de Miguel de Unamuno: edición de un soneto inédito” (Martínez Deyros 2015b). 
el tipo de reescrituras evidencia ese estado quasi finito del poema, procediendo siempre a sustituir el segmento tachado por otro, proporcionando una única opción y no varias, como era su práctica de escritura habitual.

En el caso de nuestro soneto inédito, la profundidad del descenso vendrá marcada desde la aliteración del primer verso, con la reiteración del sonido nasal $-n$ y de la vocal media -0 , nasalizada en dos de los casos. El poeta es arrastrado hacia un "fondo" que no se puede abarcar por "insondable", con lo que se acentúa aún más la sensación de inefabilidad que supondrá el arrobamiento místico. El océano representa la inconsciencia, la continuidad, el anhelo de eternidad, erigiéndose en tumba del pasado, "do yacen las memorias" y, a la vez, origen de la "visión del futuro". Futuro que es misterioso, "velado", "eterno acarno", pero ante el que no cabe arredarse y hay que enfrentarse. Esta "visión”, pues, no deja de ser un acto de la imaginación y, como tal, se vale del corazón, no solo del intelecto. Es en este porvenir donde reside la libertad con "su arbitrio soberano"; retomando, de esta forma, la idea desarrollada en los tercetos que, finalmente destinará el autor al soneto "Fortaleza", pero que en un principio formaron parte de "Resignación”. Igualmente, el ensayo “¡Adentro!” recogerá la misma noción, hasta el punto de que podemos llegar a entender el texto en prosa como posible glosa de estos versos:

Y entretanto, resignación, resignación activa, que no consiste en sufrir sin luchar, sino en no apesadumbrarse por lo pasado ni acongojarse por lo irremediable; en mirar al porvenir siempre. Porque ten en cuenta que sólo el porvenir es reino de libertad; pues así que algo se vierte al tiempo, a su ceñidor queda sujeto. Ni lo pasado puede ser más que como fue, ni cabe que lo presente sea más que como es; el puede ser es siempre futuro. No sea tu pesar por lo que hiciste más que propósito de futuro mejoramiento; todo otro arrepentimiento es muerte, y nada más que muerte. Puede creerse en el pasado; fe sólo en el porvenir se tiene, sólo en la libertad. Y la libertad es ideal y nada más que ideal, y en serlo está precisamente su fuerza toda. Es ideal e interior, es la esencia misma de nuestro posesionamiento del mundo, al interiorizarlo.

De nada sirve al poeta permanecer anclado en el pasado, pues tan solo es muerte, nada, vacío existencial, que se deberá combatir con resignación, siempre activa. El dolor que nos produce nuestra toma de conciencia con la verdadera esencia de la realidad es el que nos mantiene vivos y, solo mirando hacia el futuro, hacia ese engimático "arcano”, hallaremos la libertad y la esperanza en la eternidad. Compárese los versos finales "Robusta vida dando a la esperanza / de los recuerdos con el alma viva”, con las últimas líneas del artículo: "Espera, que 
sólo el que espera vive; pero teme al día en que se te conviertan en recuerdos las esperanzas al dejar el futuro, y para evitarlo, haz de tus recuerdos esperanzas, pues porque has vivido vivirás”. Es decir, que el hombre deberá convertir sus recuerdos en esperanzas, dejando el pasado y mirando hacia el futuro, para no caer en el aniquilamiento que le produciría la muerte sin más, la nada.

En lo referente a la cohesión semántica de los poemas aquí presentados, podemos trazar dos grandes líneas isotópicas en torno a los conceptos de RESIGNACIÓN ACTIVA y RESIGNACIÓN PASIVA, donde cada categoría semántica se relacionaría con su opuesto.

\begin{tabular}{|c|c|c|}
\hline $\begin{array}{l}\text { RESIGNACIÓN ACTIVA } \\
\text { fortaleza - firmeza }\end{array}$ & VS. & $\begin{array}{l}\text { RESIGNACIÓN PASIVA } \\
\text { debilidad - flaqueza / dureza - virili- }\end{array}$ \\
\hline dad & & \\
\hline $\begin{array}{l}\text { piedad - osadía - } \\
\text { audacia - paciencia }\end{array}$ & vS. & egoísmo - mezquindad \\
\hline corazón - amor - luz del corazón & vs. & mentira de la mente - patraña \\
\hline obras de amor & vs. & obras de ira \\
\hline $\begin{array}{l}\text { aíz divina - corriente - manantial - } \\
\text { céano }\end{array}$ & vS. & costra \\
\hline
\end{tabular}

Así, el hombre en su agonía motivada por el ansia de eternidad, precisa descender hacia el interior de su conciencia, simbolizando esta profundidad a través del isomorfismo del agua, ya sea como "manantial”, "corriente" que fluye u océano, como en el soneto inédito. Pero, el poeta se cuida de precisar desde un primer momento que del inmenso océano no nos interesan sus olas, su superficie (o "costra”), sino el "fondo", que por eterno es "insondable”. En su arrobamiento descendente el yo deberá guiarse por su "luz del corazón”, por el amor que irradia del centro de su "alma" o "pecho" y no fiarse de la "mentira” de la mente. Los débiles se dejan conducir por la "patraña” del intelecto, obviando el sentimiento. Sin embargo, solo a través de este el yo podrá experimentar el mundo que el pensamiento concibe. De ahí que hable de las "obras de amor", y no "de ira”, que distinguirán a los hombres fuertes y piadosos de los débiles y mezquinos. La lucha eterna requiere una voluntad activa para que el yo poético se reafirme su ser, en su anhelo de inmortalidad personal. Y, a su vez, conforman esta voluntad una serie de virtudes: fortaleza y firmeza, piedad, paciencia, audacia (u osadía).

Unamuno rechaza el concepto de compasión nietzscheana, pues en ella reside precisamente la fuerza del espíritu, y es débil solo aquel que se conforma 
con la nada tras la muerte, que no es otra cosa que muerte en vida. El hombre, como ser que piensa y siente, debe aspirar al más allá, a la eternidad y para ello será fundamental rechazar el arrepentimiento por las obras pasadas. De nada le sirve vivir en ese perpetuo remordimiento, pues vivir en los recuerdos del pasado es como morir en vida. Tampoco el presente “impuro” le sirve. De ahí que insista en abandonar "las memorias" yaciendo en el fondo de su conciencia o dejar “al pasado sepulto” para siempre y, en su lugar, poner nuestra mirada en el "porvenir”, que para él es el "reino de la libertad”. Por eso exhorta a su alma para que transforme sus recuerdos en esperanza, en futuro; y aunque este sea desconocido, “arcano”, “oculto”, por encerrar en sí la Esfinge, este misterio es también eternidad. Y esta es la máxima aspiración a la que debe apuntar el hombre.

\section{Conclusiones}

Como hemos visto a lo largo del presente trabajo, don Miguel compuso sonetos desde mucho antes de lo que la crítica hasta ahora había considerado. El análisis de los manuscritos de trabajo unamunianos nos confirma que fue “Resignación” el primero de todos los que compuso y, contrariamente a lo que otros hispanistas han sostenido (García Blanco 1954: 35; Cerezo 1996: 283), podemos retrotraer su fecha de redacción al año 1894. Asimismo, el estudio de estos borradores nos lleva a estimar como contemporáneo otro grupo de composiciones, con el que mantiene una evidente cohesión tanto temática como formal: "Fortaleza”, “Piedad” y el inédito, “Del insondable fondo del océano”. En efecto, a pesar de las numerosas reescrituras que sufrieron estos sonetos, habría que considerarlos anteriores al Diario Íntimo, por lo que, se contradiría, en parte, las afirmaciones de Cerezo Galán, que fecha “Resignación” en 1901 y, por tanto, muy posterior a la escritura de su diario privado: “la actitud de Unamuno a comienzos de siglo estaba ya lejos del tono piadoso y hasta apaciguador del Diario” (1996: 284). Por consiguiente, estimamos que don Miguel mantuvo esta “actitud" vacilante y contradictoria durante toda su vida, expresando en unos casos un matiz más “piadoso” y “apaciguador”, y en otros, más combativo y agónico en relación al enigma de la eternidad y a la toma de conciencia dolorosa que le supone su enfrentamiento con el tiempo y la propia muerte. En efecto, son las dos caras de una misma moneda, el hombre contemplativo y el hombre agónico, dos formas de pensar sintiendo y de sentir pensando, que se suceden como “alternancia, no simultáneamente, y no hay guerra entre ellas” (Blanco Aguinaga 1975: 47). 


\section{Bibliografía}

BLANCO AGUINAGA, C. (1975). El Unamuno contemplativo. Barcelona: Laia. BLASCO, J. (2011). Poética de la escritura: el taller del poeta. Ensayo de crítica genética (Juan Ramón Jiménez, Francisco Pino y Claudio Rodríguez). Valladolid: Cátedra Miguel Delibes.

BLÁZQUEZ GONZÁLEZ, J. A. (2007). Miguel de Unamuno y Bernardo G. de Candamo: amistad y epistolario (1899-1936). Madrid: Ediciones 98.

CELMA VALERO, M. ${ }^{a}$ P. (2002). "Miguel de Unamuno, poeta simbolista”. Anales de Literatura Española 15: 93-107.

CEREZO GALÁN, P. (1993). "El mal del siglo y la vuelta a lo trágico”. Curso Universitario: Filosofía y tragedia (A propósito de Miguel de Unamuno). http://www.march.es/conferencias/anteriores/voz.aspx?p1=22145\&l=1 (Acceso 27 Febrero 2015).

CEREZO GALÁN, P. (1996). Las máscaras de lo trágico. Filosofía y tragedia en Miguel de Unamuno. Madrid: Trotta.

DURAND, G. (2005). Las estructuras antropológicas del imaginario: introducción a la arquetipología general. Madrid: Fondo de Cultura Económica.

FIORASO, N. (2014). "Unamuno, traductor de Spencer”, Pensar la traducción: la filosofía de camino entre las lenguas. Actas del Congreso (Talleres de comunicaciones). Madrid, septiembre de 2012. Madrid: Universidad Carlos III de Madrid: 221-230.

GARCÍA BLANCO, M. (1954). Don Miguel de Unamuno y sus poesías: estudio y antología de textos poéticos no incluidos en sus libros. Salamanca: Universidad de Salamanca.

GRÉSILLON, A. (1994). Éléments de critique génétique: lire les manuscrits modernes. Paris: PUF.

IMÍCOZ BENZUA, T. (1996). La teoría poética de Miguel de Unamuno. Navarra: EUNSA.

MARÍAS, J. (1968). Miguel de Unamuno. Barcelona: Gustavo Gili.

MARTÍNEZ DEYROS, M. (2015a). "El proceso redaccional de Poesías de Miguel de Unamuno: intento de reconstrucción”. Artifara 15: 21-41.

MARTÍNEZ DEYROS, M. (2015b). "Soledad de Miguel de Unamuno: edición de un soneto inédito”. Ogigia 18: 95-108.

PRELLWITZ, N. VON (1969-1970). Estudios estilísticos sobre sonetos de Unamuno (tesis doctoral).

ROBLES, L. (1997). Epistolario americano (1890-1936). Salamanca: Ediciones Universidad de Salamanca. 
UnAMUNO, M. DE (1999). Obras Completas, IV. Poesías. Madrid: Fundación José Antonio de Castro.

UNAMUNO, M. DE (2007). Obras Completas, VIII. Ensayos. Madrid: Fundación José Antonio de Castro.

VALERA, J. (2008). Correspondencia. Volumen VII (1900-1905). (Ed. de Leonardo Romero Tovar). Madrid: Castalia. 